\title{
Forecast accuracy in demand planning: A fast-moving consumer goods case study
}

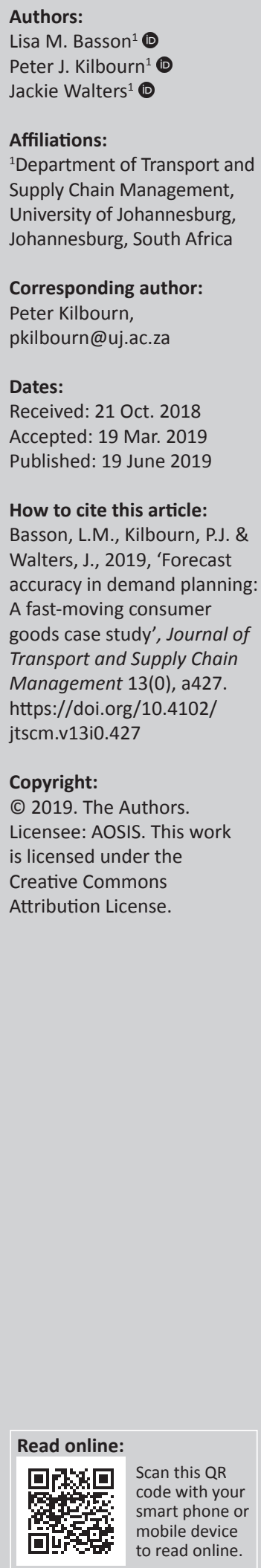

Background: An established South African fast-moving consumer goods (FMCG) manufacturer, Company A, sought to address an underperforming supply chain through an attempt to improve demand planning accuracy. A need arose within the organisation for an assessment of the impact of this intervention. A literature gap was also identified, taking into account the limited number of relevant case studies that exist in academic literature.

Objectives: The primary objective of this study was to establish whether or not the demand planning interventions of Company A had a positive impact on the performance of the supply chain under investigation. In support of this primary objective, the secondary objectives were to determine and compare the pre- and post-intervention demand planning activities and performance of Company A.

Method: A case study research design was used focusing on Company A. The researcher sourced evidence through a secondary quantitative data analysis and primary data collection through interviews with personnel directly involved in the demand planning process at Company A.

Results: From mean absolute percentage error calculations, it was found that the focal company's demand planning process intervention had reduced the errors in demand forecasting for all classifications of stock keeping units analysed.

Conclusion: The demand planning interventions applied by Company A had a positive impact on the overall supply chain performance. A positive relationship was found between a well-informed, team-based and technology-assisted approach to demand planning and improved forecasting accuracy within an FMCG company.

Keywords: demand planning; forecasting; fast-moving consumer goods; forecast accuracy; mean absolute percentage error.

\section{Introduction}

South African fast-moving consumer goods (FMCG) companies operate in an increasingly competitive environment (KPMG 2016a:1; Pricewaterhouse Coopers 2012:2). Furthermore, inaccurate demand forecasting is regarded as a main cause of uncertainty for FMCG companies operating in South Africa (Sanchez Rodrigues \& Potter 2013).

Demand planning is an operational supply chain management (SCM) process comprising several steps in developing reliable forecasts (Cassettari et al. 2017:49-50). Effective demand planning contributes to the accurate alignment of inventory levels with peaks and dips in demand (balancing supply and demand), meeting customer expectations, remaining competitive and thus improving profitability for a specific channel or product item (Metcalfe 2012:58; Rouse 2010; Supply Chain Resource Cooperative 2004).

Demand management (i.e. balancing supply and demand) is a key factor in improving the efficiency of supply chain operations (Croxton et al. 2002). There is also growing proof that companies that have implemented demand-driven supply chains experience an increase in sales, a reduction in operating expenses and an improvement in working capital (KPMG 2016b:2). The supply chain planning process is often the one with the largest performance gap; it is also the one process most often misunderstood by supply chain and business executives. The process also plays a fundamental role in overall supply chain success and is often a key source of competitive advantage (Bursa 2014; Cecere 2014; Chase 2016). 
Balancing supply and demand is a common problem in manufacturing organisations across all industries; it is becoming increasingly important to achieve this balance (Coker \& Helo 2016:564; Supply Chain Market 2018). This problem is exacerbated in the context of FMCG organisations because of the high demand for product availability, which characterises FMCG. Therefore, a push-based manufacturing model is required (Bellini 2015; Coyle, Bardi \& Langley 2003:224).

\section{Background}

Company $\mathrm{A}$ is an established FMCG manufacturer, with different business units servicing different FMCG market needs in Africa. When interviewed on 17 May 2016, the supply chain executive of the company disclosed that following a supply chain performance metrics review, it was concluded by senior management of Company A that the company had an underperforming supply chain. The internal performance metrics used to determine supply chain performance in the company related mainly to customer service levels and logistics costs as a percentage of sales. The underperformance was ascribed to inaccurate demand planning; consequently, an intervention to improve demand planning accuracy in the affected supply chain was instituted in October 2013.

From the interview with the company executive, it also transpired that at the time of the commencement of this study in 2016, the company had conducted a baseline review of the impact of its demand planning intervention, confirming the improvement of the respective supply chain in terms of the internal benchmarks used (customer service levels improved by $9 \%$ and logistics costs as a percentage of sales decreased by $1.8 \%$ ). However, the company had not formalised the process changes in detail for future reference, nor had demand planning performance been assessed in detail. Furthermore, a limited number of case studies around demand planning activities within the context of the local South African FMCG sector exist. Therefore, this research attempts to close this gap by providing further insight into the relationship between demand planning processes and supply chain performance at an FMCG company.

The primary research objective of this study was to determine the effectiveness of the demand planning intervention of Company A on the supply chain's performance, from a comparison of pre- and post-intervention demand planning activities. In support of this primary objective, the secondary objectives were to determine and compare the pre- and postintervention demand planning activities and performance of Company A.

\section{Literature review}

\section{Demand planning and supply chain performance}

Demand management can be considered a supply chain process, where the capabilities of the entire supply chain are matched with the requirements of customers (Croxton et al. 2002). Demand management entails more than demand planning. It also makes provision for the creation of a balance between supply and demand, and improves flexibility and reducing variability (Croxton et al. 2002). A balance between customer demand and an organisation's supply ability is required for an organisation's success (APICS 2017), therefore contributing to overall supply chain and organisational success (Myerholtz \& Caffrey 2014; Michigan State University 2019).

According to Levenbach (2011:6), 'demand management is about preparing for, and ensuring that the right amount of the right product is in the right place at the right time at the right price'. This process includes demand forecasting which is used as an enabler for synchronised procurement, production and distribution processes (Croxton et al. 2002).

\section{Importance of the demand planning process for fast-moving consumer goods companies}

Owing to the push-manufacturing nature of the FMCG industry, production takes place prior to final demand being known. Push planning is most suited to segments that have dependent demand, where scale economies can easily be achieved, supply uncertainty exists and capacity limitations are evident, or in the instance of seasonal demand which requires a build-up of stock to meet a seasonally related surge in demand (Coyle et al. 2003:224).

Because of its structure, the FMCG industry relies heavily on forecasted demand figures (Gupta \& Kumar 2013:10; Muller 1999:6), as these dictate all downstream processes, such as inventory management, procurement, manufacturing capacity planning, resource and transportation planning - in other words supply chain execution and ultimate delivery on customer service levels (Myerholtz \& Caffrey 2014; Sonawane 2011). These downstream processes and associated impact on customer service have a direct impact on overall organisational performance (Sonawane 2011). The timeous flow of information and interpretation of information are important to the development of the demand forecast, which plays an important role in the demand planning process and has an impact on the organisation's performance, that is, the bottom line (Vriens \& Versteijnen 2006:9).

Forecasting accuracy has a major impact on inventory investments (Bonney 2009; Fisher, Raman \& McClelland 2000). Inaccurate forecasts are associated with excess inventory, increased transportation costs and lost sales (Bonney 2009). To improve forecasting accuracy, organisations have to track and analyse forecasting errors so that it is known when and why these errors are most likely to occur. Ideally, the organisation also needs to know the margin of error so that the potential impact of forecasting errors can be determined and action plans can be developed (Fisher et al. 2000).

Therefore, demand forecast accuracy is critical in the demand planning process and can be considered a robust measure in the assessment of the performance of the demand plan for Company A. 


\section{Demand planning process}

The demand planning process balances customers' requests with the organisation's supply abilities (Croxton et al. 2002). Fast-moving consumer goods organisations trade primarily on volume (Basu 2016:38) and products can often easily be substituted by consumers. As FMCG organisations trade primarily on volume, not meeting demand is as problematic as excess demand (Supply Chain Market 2018).

According to Sonawane (2011) and Chase (2016:106), the first step towards a best-in-class demand planning environment is to set up a formal demand planning process, which requires the introduction and integration of demand planning systems. The creation of a demand planning system should include the following: setting objectives for demand plans; developing metrics for 'business units'; classifying or identifying purchasers' important product items; ensuring location visibility and formalising the frequency of the forecasting process (i.e. creation, review and publishing of demand plans), with specific time horizons attached (Sonawane 2011) and ensuring that the right information technology (IT) is implemented to support these activities (Bindra 2014).

Recognition and understanding of the different planning horizons within the value chain ecosystem, in the context of the FMCG supply chain, is essential. In addition, it is necessary to formulate a plan to cleanse historical data. Data cleansing is the process of identifying, amending or removing inconsistencies in a set of data (Muro 2016). Historical data are the primary input into the statistical models used to generate the demand plan (Ameson 2015; Sonawane 2011). The level at which the forecast must be generated can then be decided, and the following processes should be implemented:

- developing a planning protocol, in the instance of market (short-term) events and promotional event forecast development

- creating a forum for the development of a consensus forecast (to form part of the sales and operations planning [S\&OP] process)

- reconciling the top-level collaborative forecast with lower levels, before sharing this forecast with operations for replenishment or manufacturing purposes (Sonawane 2011).

Demand planning is a cyclical process. As such, the last step in the cycle is a formal review of the forecast against the current sales figures, using metrics related to forecast accuracy evaluation. To manage erratic demand, planning strategies should include the following: management of supply buffers; inventory buffers; capacity buffers; strategies to reduce cycle time; strategies to postpone production as far as possible and processes, which are collaborative (Gangadharan 2007).

\section{Information technology tools}

According to Myerholtz and Caffrey (2014), a best-in-class forecasting tool (which contributes to the creation of an accurate demand plan) should include an improved forecasting process that focuses on the following:

- Application of a statistically driven model requiring little or no manual effort or intervention.

- Use of several distinct data sources providing information about all the primary drivers of demand.

- The application of a model, which predicts consumer sales and learns customers' ordering patterns to provide shipment predictions.

- The model used must 'learn' over time, adjusting to changes in demand and ordering behaviour to enhance accuracy levels.

- With the improved forecasting approach, accuracy must be aligned and assessed against industry-specific, best-inclass averages.

All of these are fundamental considerations in any attempt to develop a supply chain that performs at an optimal level and is ultimately all supported by IT.

According to Palmatier and Crum (n.d.:12), different types of software-based tools are used in demand planning. These are tiered according to functionality: the first providing the lowest level of integration and functionality, and the last providing the highest level of integration and functionality; they are as follows:

- stand-alone statistical forecasting software

- demand planning packages that are integrated and include statistical forecasting, promotions forecasting, forecasting of product life cycles and sales planning information

- software packages that provide sales planning and customer relationship management functionality

- collaborative planning software packages that enable the communication of planned promotions, scheduled purchases, forecasts and consumer point-of-sale data

- software suites that incorporate all the above into enterprise resource planning and supply chain management software.

The use of information technology (IT) tools facilitates the demand planning process and improves the reliability of the demand plan. Common capabilities of such tools include the following: integration with source systems, historical trend analysis and demand shaping, data classification, planning by exception, flexibility and performance measurement (Bindra 2014).

Some well-known IT demand planning tools currently available on the market are JDA Demand by JDA Software, SAP-Supply Chain Management by SAP, Forecast Management by Demand Solutions and Demantra by Oracle (Bindra 2014; G2 Crowd, Inc. 2017). When IT tools are used effectively, they can improve the capability and performance of the demand planning process. This improvement can, in turn, result in an improvement of the organisation's supply chain efficiency, which will lead to better overall results (Bindra 2014). 


\section{Techniques to assess forecast accuracy}

$\mathrm{ABC}$ analysis is a control technique used to better inform the management of inventory and can be applied to a wide range of inventory items (Fritsch 2015). The primary purpose of the $\mathrm{ABC}$ analysis is to provide service with the least amount of cost and effort (Wild 2002:37). The ABC analysis and associated classification make reference to three categories applicable in the business context (Fritsch 2015). As a rule of thumb, A-classified stock items make up $10 \%$ of stock numbers and provide up to $65 \%$ of turn over; B-classified stock items make up $20 \%$ of stock numbers and contribute $25 \%$ of turnover and C-classified stock items make up $70 \%$ of stock numbers and only provide for $10 \%$ of total turnover (Wild 2002:36). If mean absolute percentage error (MAPE) is applied to assess forecast accuracy, it is best to classify stock items accordingly, as lower volume items can skew the final number. If ABC classifications are applied, separate values can be calculated for each classification (Stellwagen 2011).

The ABC analysis was applied to assess and analyse the impact of the demand planning intervention across the different priority stock keeping units (SKUs) at Company A and to understand where the most impact was made as per the implementation of these interventions.

The MAPE is a popular metric used to assess forecast accuracy (Chase 2016:128; Clements 2016; Gilliland \& Platt 2010:22; Kim \& Kim 2016:669). Mean absolute percentage error allows for the comparison of forecasts of differing scales and from different series of data (Chase 2016:129; Gilliland, Sglavo \& Tashman 2015:181; Wood 2012). The MAPE formula, as applied against the sales data as provided by Company A, is expressed in Figure 1.

$$
\left(\frac{1}{n} \sum \frac{\mid \text { Actual }- \text { Forecast } \mid}{\mid \text { Actual } \mid}\right) * 100
$$

Source: Chase, C.W., 2016, Demand-driven planning: A practitioner's guide for people process, analytics, and technology, ProQuest eBooks Central, pp. 129, viewed 18 February 2018, from https://0-ebookcentral-proquest-com.ujlink.uj.ac.za/lib/ujlink-ebooks/detail. action?docID=4622921; Stellwagen, E., 2011, 'Forecasting 101: A guide to forecast error measurement statistics and how to use them', Forecast PRO, viewed 08 February 2018, from http://www.forecastpro.com/Trends/forecasting101August2011.html

FIGURE 1: Mean absolute percentage error formula. $n$ is representative of the number of periods over which the error was measured.

TABLE 1: Positive and negative aspects of mean absolute percentage error.

\section{Positive}

Mean absolute percentage error is best for working with large volumes of data (Stellwagen 2011).

\section{Mean absolute percentage error} allows for the comparison of

forecasts of differing scales and from

different series of data, as such is

often referred to as a metric, that is,
'scale independent' (Chase 2016:129,

Gilliland et al. 2015:181; Wood 2012).

Calculating error measurement statistics across multiple items for one period of tim can prove to be problematic (Chase

2016:129). Calculation of an aggregated

MAPE is common practice (Stellwagen 2011).

MAPE, mean absolute percentage error.
The positive and negative aspects associated with the application of MAPE are detailed in Table 1.

Other well-known forecast accuracy assessment methods for demand planning include the mean absolute deviation and the mean square error (MSE). Mean absolute deviation is best suited to the assessment of low demand or volume SKUs (Stellwagen 2011) and is scale dependent, while the MSE is also scale dependant (Hyndman 2010) and is best suited to picking up large forecast errors, that is, in application, error terms with larger magnitudes will be exaggerated, also limiting relevance in terms of application (Mosalaosi 2016). Mean absolute percentage error allows for accessible comparison, that is, percentage values, making it a suitable choice with regard to actionable insight and understanding in the broader management context (Hyndman 2011). For these reasons, MAPE was the preferred method used in this study.

\section{Methodology}

This study followed a case study research approach that is aligned with a pragmatic worldview approach (Creswell 2009:13). This was an appropriate methodology for this study, as it took place over a defined period of time. Further supporting this choice of methodology is the nature of data collection, which was done from multiple sources using more than one method. The environment under analysis presented rich context-specific data related to the research questions. The focal organisation in this case study is referred to as Company A, as the company gave the go-ahead for this research, provided that it remained anonymous. A confidentiality agreement was signed in this respect.

For Company A, a detailed analysis of quantitative secondary data relevant to 443 SKUs was undertaken to assess forecast accuracy. Stock keeping units were analysed with regard to actual sales, forecast errors or accuracy and their Pareto classifications (i.e. ABC analysis) (Fritsch 2014; Wild 2002:36-40). The analysis considered SKUs individually and holistically, to draw suitable inferences. Stock keeping units were first assessed quantitatively using MAPE.

To gain insight into the demand planning process, pre- and post-intervention primary data were collected by means of interviews with four key personnel from Company A. The supply chain manager was initially interviewed, and supplied the secondary data used to assess demand planning accuracy, pre- and post-intervention. The marketing manager, demand planner and customer manager were interviewed to understand the interventions and how these directly impacted their particular function within the supply chain under investigation. The data were used to assess the preand post-intervention performances of the supply chain under investigation, and to determine whether or not the inefficiencies and gaps had been resolved through these interventions as per the study objectives. The only changes made to the supply chain during this period were those related to the changes or interventions detailed within the context of this study. 


\section{Ethical considerations}

This article followed all ethical standards for a research without direct contact with human or animal subjects.

\section{Findings}

The results were analysed and categorised into two distinctive phases, namely, the pre- and post-intervention phases. The intervention was implemented in October 2013; therefore, the impact of the intervention is assessed from November 2013 - the post-intervention phase. The number of periods falling into the pre- and post-intervention phases differs, as pre-intervention data were only available for 13 periods (months), while post-intervention data are available for 33 periods (months). Consequently, the analysis includes a direct comparison of the 13 months' pre-intervention versus the 13 months' post-intervention. For the purposes of analysis, the full period under investigation is from October 2012 to July 2016 (46 months or periods, in total). The preintervention period is from 01 October 2012 to 31 October 2013, while the post-intervention period falls between 01 November 2013 and the end of July 2016, as per the intervention timeline detailed in Figure 2.

All 443 SKUs with a corresponding set of data in the supply chain under investigation were classified using $\mathrm{ABC}$ analysis, based on actual sales volume per item for the period July 2015 to July 2016. Based on the Pareto principle (80/20 rule), items with annual sales exceeding 130000 units were classified as A items; those with a demand of between 130000 and 60000 units, as B items and those with a demand below 60000 units, as C items. Of the 443 SKUs, 45 SKUs were classified as A items, 39 SKUs as B items and 359 SKUs as
C items. Such a classification contributes to enhanced insight into the supply chain to assist in more accurately assessing the results of the interventions taken by Company A to improve forecast accuracy.

\section{Forecast accuracy results}

The MAPE was used as the primary metric for forecast accuracy assessment, as it is ideal for assessing large volumes of data because of its scale sensitivity, and associated ease of comparison thereof. From Figure 2 and Table 1, it follows that the intervention in the demand planning process resulted in an improvement in forecast accuracy for all SKUs, from the pre-intervention period to the post-intervention period, of $2.7 \%$ over 13 periods and $7.18 \%$ over 33 periods, reducing the MAPE to $14.71 \%$. The improvement was more pronounced at a total SKU level, after the 13-month period, than in the initial stages of post-intervention.

For the A-classified SKUs, the MAPE dropped by $4.9 \%$ to $16.1 \%$ (Table 2). For B-classified items (Table 2), the forecast

TABLE 2: Mean absolute percentage error forecast accuracy improvement: Pre- and post-intervention.

\begin{tabular}{lclcc}
\hline Pre-intervention & $\begin{array}{c}\text { MAPE } \\
(\mathbf{\%})\end{array}$ & Post-intervention & $\begin{array}{c}\text { MAPE } \\
(\mathbf{\%})\end{array}$ & $\begin{array}{c}\text { MAPE forecast accuracy } \\
\text { improvement (\%) }\end{array}$ \\
\hline All SKUs & 21.89 & All SKUs (13 periods) & 19.19 & +2.70 \\
(13 periods) & 21.89 & All SKUs (33 periods) & 14.71 & +7.18 \\
A SKUs & 21.00 & A SKUs (13 periods) & 20.30 & +0.70 \\
(13 periods) & 21.00 & A SKUs (33 periods) & 16.10 & +4.90 \\
B SKUs & 27.60 & B SKUs (13 periods) & 17.20 & +10.40 \\
(13 periods) & 27.60 & B SKUs (33 periods) & 15.10 & +12.50 \\
C SKUs & 25.40 & C SKUs (13 periods) & 19.10 & +6.30 \\
(13 periods) & 25.40 & C SKUs (33 periods) & 14.00 & +11.40 \\
\hline
\end{tabular}

MAPE, mean absolute percentage error; SKUs, stock keeping units.

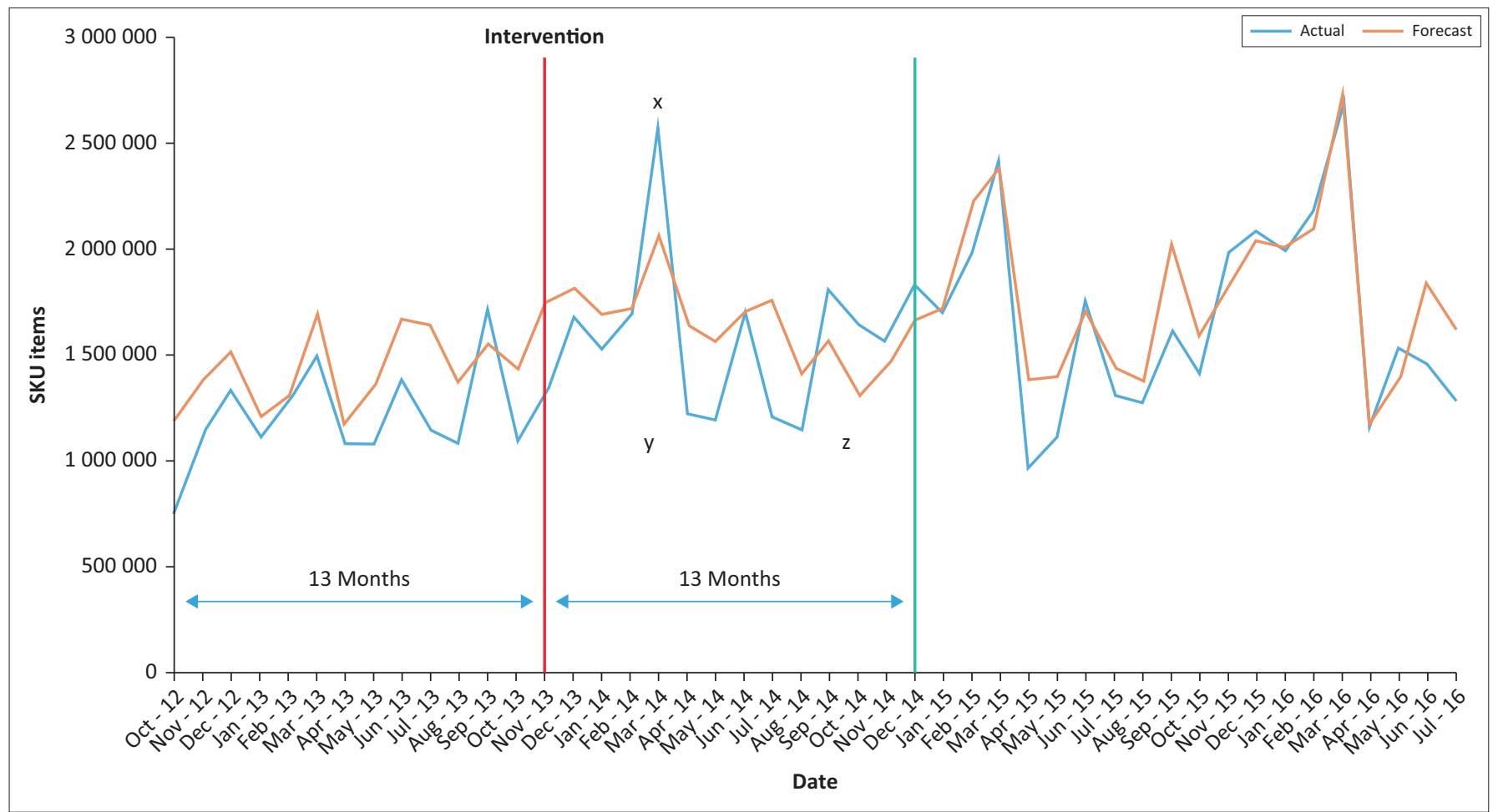

SKU, stock keeping units.

FIGURE 2: Forecast accuracy assessment for all 443 stock keeping units. 
accuracy improved, by $10.4 \%$ in the first 13 months, postintervention; at a total level, a $12.5 \%$ improvement in forecast accuracy was presented. For C-classified items (Table 2), there was an improvement of $6.3 \%$ in forecast accuracy within the first 13 months, post-intervention, and a further improvement of $5.1 \%$ thereafter, resulting in a total improvement of $11.4 \%$ in demand forecast accuracy since the initial intervention.

\section{Changes in the demand planning process at Company A}

The interviews revealed that substantial changes were made to the demand planning process at Company $\mathrm{A}$, as outlined in Table 3.

The most notable differences in the demand planning process, pre- and post-intervention, are the additions to the demand plan preparation and team review process (step 4). In contrast to the pre-intervention process, the post-intervention process includes 63 promotional categories of products forecasted by the customer teams in value terms. Moreover, the demand planner then converts these values into volume terms. Torch, an econometric software product that includes a consideration of factors that may influence consumer propensity to spend (i.e. the immediate consumer environment), is then used to assess the volume forecast against the various economic factors detailed.

A fifth step has been inserted to allow a pre-demand review. As a result, the demand planner now performs or facilitates additional actions to create and present the final demand plan. Each of these additional actions focuses on improving the accuracy of the forecast.

All interview participants agreed that the new demand planning process had mostly addressed the limitations associated with the pre-intervention process, namely:

- the top 50 SKUs were assessed by margin, as opposed to volume or value

- a lack of consensus regarding the best approach to forecast development existed

- the executive team was excluded from the sign-off process

- the customer team only provided input for the top 50 SKUs by margin
- SKUs or items not included in the top 50 were reviewed (i.e. forecasts finalised) in a separate meeting between the demand planner and marketing manager. Thus, no input from other key role players on the forecast for most SKUs was obtained.

The participants highlighted how the inefficiencies in the demand planning process had been addressed, summarised as follows:

- The TM1 table program now interfaces with the database.

- Customer teams now re-classify forecasts from the top 50 SKUs (by gross margin) into 63 promotional categories, providing more comprehensive forecast coverage.

- The Torch econometric modelling software enhances forecast accuracy.

- Pre-demand review meetings are now held to ensure that the final demand review with the executives focuses on developing consensus as opposed to formulating a specific number.

However, from the feedback during interviews, it seems that further improvement iterations of the demand planning process are needed to improve the forecasting accuracy. Issues to resolve include the following:

- A value-to-volume conversion is required because the customer team forecasts in value terms across the 63 promotional categories, resulting in an inaccurate volume forecast prepared by the demand planner.

- There seems to be an overreliance on tacit knowledge and a single demand planner to collect, clean and collate data (over and above the pre-demand review and demand review meeting preparations) for all the SKUs.

- Forecasting guidance is expected from personnel with a long tenure, to provide knowledge of demand fluctuations, promotions and previous mistakes and learnings. (No central repository for knowledge of this nature exists.)

- The Excel document seems to be a point of contention for all those involved in the demand planning process, as it is cumbersome because of its large size. As a result, it is time-consuming to update and is, therefore, not updated in a timely manner.

TABLE 3: Comparison: Pre- and post-intervention demand planning processes.

\begin{tabular}{ll}
\hline Demand planning cycle period & Process pre-intervention -1 month \\
\hline Step 1: Forecast generated & $\begin{array}{l}\text { The statistical forecast was generated using the } \\
\text { TM1 tool } \dagger \text { (historical data provided the primary } \\
\text { foundation for this forecast) }\end{array}$ \\
Step 2: Team input & $\begin{array}{l}\text { The TM1 forecast was then shared with the } \\
\text { marketing and customer teams for them to }\end{array}$
\end{tabular}

Process post-intervention - 1 month

The demand planner now generates a report using the Oracle Micro-Strategy reporting tool. This reflects actual sales from the previous month. The report is exported into an Excel This reflects actual sales from the previo
document to update the forecast report

This report is shared with the marketing team. Pre-demand reviews based on the marketing provide input 列 more representative of the current operating environment Step 3: Team review or team Day-long meetings were held considering only the
input input supply chain of 663 SKUs)

Step 4: Demand plan The remaining SKUs in the supply chain were then finalisation or preparation forecasted by the demand planner and marketing manager, without any input from any other teams

Step 5: Demand plan shared with production or demand plan finalisation The plan was then cascaded down to the production team

The customer team provides the demand planner with the Sources of Growth document that breaks each of the 663 SKUs into 63 promotional categories from which sales projections for the month ahead are made in value terms, not volume terms

The demand planner then converts this value information into volume information to feed into the final demand plan. The demand planner reviews a forecast report from Torch which is compared to the amalgamated projects and inputs from the various teams

The demand planner presents the demand plan to the marketing managers, EXCO representatives and customer or sales team manager at the demand review meeting. Consensus on projections are reached and signed off in this meeting (consensus)

Step 6: Demand plan shared

The plan is then cascaded down to the production team

with production

T. TM1 is a table manager program that enables an Excel document to interact directly with a database.

\$. Torch is an econometric computer program that focuses on the prediction of factors that may influence consumer propensity to spend (i.e. the immediate consumer environment) 
- This, in turn, means that inputs related to promotions are not current, which could distort the overall demand planning process. In summation, the demand planning process is still mostly manual (which is less than ideal).

\section{Discussion of findings}

The research problem underpinning this study centred around the lack of information available regarding the impact of demand planning interventions on demand planning accuracy for Company A. The primary research objective was to establish whether or not the demand planning interventions of Company A had a positive impact on the performance of the supply chain under investigation. In support of this primary objective, the secondary objectives were to determine and compare the pre- and post-intervention demand planning activities and performance of Company A.

From a MAPE analysis of Company A's pre- and postintervention forecasting accuracy, a definite improvement in the accuracy of the demand planning process was recorded at Company A after the intervention process. It is further evident that the degree of improvement differed per SKU classification. B-classified SKUs showed the greatest improvement in MAPE over the 13 periods post-analysis and continued for the full post-period analysis. The C-classified SKUs recorded a similar improvement over the 33 periods. However, the high-volume A-classified SKUs, critical to the business, recorded the lowest percentage in forecast accuracy improvement. Nevertheless, as all three SKU categories recorded a forecast improvement, it is possible to infer that the interventions introduced had a positive impact on the supply chain because of improved demand forecast accuracy.

It follows that the changes in the demand planning process have resulted in an improvement in overall supply chain performance, as evident from a review of the company metrics:

- Customer service levels improved from 86\%, preintervention to $95 \%$, post-intervention - an improvement of nine per cent.

- Logistics costs as a percentage of sales decreased from $7.8 \%$, pre-intervention to $6 \%$, post-intervention - an improvement of $1.8 \%$.

- Of all Company A's supply chains, the one under investigation moved from ranking in ninth position in terms of customer service, pre-intervention, to ranking in second position, post-intervention - an improvement of seven places.

During the research period, no other changes or activities related to the supply chain were instituted. From the comparison of pre- and post-intervention results, it is reasonable to conclude that a relationship exists between the improvement in the demand planning process and supply chain performance, as measured by customer service levels, sales as a percentage of logistics cost and internal supply chain ranking, across the total business.
In support of this evidence, the customer manager confirmed that the demand planning process had, indeed, improved. Similarly, and in even stronger terms, the marketing manager attested to this improvement. The increased visibility and engagement that occurred because of the new demand planning process prompted the marketing team to focus on further improving forecast accuracy.

\section{Conclusion and recommendations}

In conclusion, Company A complied with Sonawane's (2011) requirements for achieving a best-in-class demand planning environment. These interventions include the following:

- A planning protocol is now in place, and promotional events are incorporated into the forecast (as per the Sources of Growth document, which considers the various SKUs in the supply chain against promotional categories).

- The demand plan is now presented in a meeting focused on reaching consensus on the forecast for the upcoming planning cycle.

- A much greater degree of collaboration now exists across the different departments and associated tiers. Brand managers are involved in the pre-demand reviews, and customer team members are required to provide inputs into the Sources of Growth document (Excel document).

For Company A to improve forecast accuracy even further, Myerholtz and Caffrey's (2014) recommendation could be followed. They suggested the incorporation of statistically driven models that require little to no manual effort. Although this is not Company A's current practice, in interviews with key personnel they indicated that a move to Demantra (Oracle demand planning software) was imminent in the demand planning process. Demantra is a software tool which offers 'multi-dimensional data modelling functionality, flexible data hierarchies for up-to-date demand visibility and one number planning' (Oracle 2015:1). The implementation of Demantra would aid in overcoming the challenges associated with the use of the oversized Excel document.

Insufficient resources remain a challenge for the demand planning team, as only one team member is responsible for conducting all the planning activities for all the SKUs. As a result, pre-demand reviews, which should include the customer team to further improve demand understanding and associated forecast accuracy, are still limited to the marketing team. However, the collection and use of data from several sources are a best-in-class practice that Company A has adopted, although neither order pattern prediction nor a learning model framework is in place yet. The implementation of such measures should be considered in the planning for future improvements in the demand planning process at Company A.

Based on the findings of this research, management needs to ensure that the demand planning team is appropriately resourced and that teams are collaborating to develop forecasts that are indicative of the broader organisation and 
requirements. Failure to ignore broader market indicators and to have the right software in place can result in adding more pressure to the organisation.

This study has contributed some insights into the relationship between the demand planning process and supply chain performance at an FMCG company. It may be inferred that, because of the demand planning interventions, overall supply chain performance has improved. This causal relationship can be assumed with near-absolute certainty because no other major interventions or measures were put in place during the research period for the specific supply chain under investigation. As such, pre- and post-intervention demand planning activities have been carefully explored and compared.

\section{Limitations}

Findings cannot be generalised to all supply chains of the company or to similar supply chains in the industry, as the study is limited to one company and only one supply chain under the company's operational control. Demand forecast accuracy (MAPE) is used as the primary metric for supply chain performance. This is a limitation, as various other factors drive supply chain performance. Supply chain planning incorporates functions over and above forecasting and demand planning. These include inventory distribution planning, and capacity planning and scheduling for manufacturing plants. This means an improvement in forecast accuracy may be attributable to more than the demand planning process and should be considered as future areas of investigation.

\section{Future research}

Future research could replicate this study in the same organisation to ascertain the longer-term impact of the interventions applied. The study may also be replicated in other similar organisations in the FMCG industry, allowing a comparison of both processes and demand forecasting accuracy levels between organisations.

\section{Acknowledgements}

\section{Competing interests}

The authors declare that they have no financial or personal relationships that may have inappropriately influenced them in writing this article.

\section{Authors' contributions}

L.M.B. wrote the article from the findings of her MCom dissertation at the University of Johannesburg. P.J.K. acted as the supervisor of the dissertation and assisted with the writing of the article. J.W. acted as the co-supervisor of the dissertation and reviewed the article and made suggestions and revisions.

\section{Funding information}

This research received no specific grant from any funding agency in the public, commercial or not-for-profit sectors.

\section{Data availability statement}

Data sharing is not applicable to this article as no new data were created or analysed in this study.

\section{Disclaimer}

The views expressed in this article are those of the authors and not an official position of the affiliated institutions.

\section{References}

APICS, 2017, APICS dictionary, Version 2.1, Mobile Application Software, viewed 07 August 2017, from http://www.apics.org/apics-for-individuals/apps/apics-apps.

Ameson, R., 2015, 'Demand-driven forecasting and the need for clean data', Bluefin Solutions, viewed 15 March 2018, from http://www.bluefinsolutions.com/ insights/rebecca-ameson/december-2015/demand-driven-forecasting-and-theneed-for-clean-d.

Basu, R., 2016, Managing projects in research and development, Routledge, Abingdon.

Bellini, J., 2015, 'Inventory replenishment: Why push when you can pull?', Inbound Logistics, viewed 11 February 2015, from http://www.inboundlogistics.com/cms/ article/inventory-replenishment-why-push-when-you-can-pull/.

Bindra, T.S., 2014, 'Role of information technology in demand planning', Linkedln viewed 07 August 2017, from https://www.linkedin.com/pulse/2014072523473052976636-role-of-information-technology-in-demand-planning.

Bonney, J., 2009, 'The great chase: Supply chain synchronicity (cover story)', Journal of Commerce 10(25), 12-16, viewed 02 February 2019, from http://0-search.

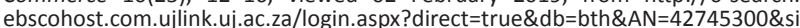
te=ehost-live\&scope=site.

Bursa, K.L., 2014, 'Achieving demand planning excellence', The European Business Review, viewed 01 July 2017, from http://www.europeanbusinessreview.com/ achieving-demand-planning-excellence/.

Cassettari, L., Bendato, I., Mosca, M. \& Mosca, R., 2017, 'A new stochastic multi source approach to improve the accuracy of the sales forecasts', Emerald Insight 19(1), 48-64, viewed 22 June 2017, from https://doi.org/10.1108/FS-07-2016-0036.

Cecere, L., 2014, 'A practitioner's guide to demand planning', Supply Chain 247, viewed 25 June 2016, from http://www.supplychain247.com/article/a_ practitioners_guide_to_demand_planning/leadership.

Chase, C.W., 2016, Demand-driven planning: A practitioner's guide for people, process, analytics, and technology, ProQuest eBooks Central, viewed 18 February 2018 from https://0-ebookcentral-proquest-com.ujlink.uj.ac.za/lib/ujlink-ebooks/detail. action?docID=4622921.

Clements, B., 2016, 'The absolute best way to manage forecast accuracy', Axium Group, viewed 21 July 2017, from http://www.axsiumgroup.com/the-absolutebest-way-to-measure-forecast-accuracy-2/.

Coker, J. \& Helo, P., 2016, 'Demand-supply balancing in manufacturing operations', Benchmarking: An International Journal 23(3), 564-583. https://doi.org/10.1108/ BIJ-04-2014-0028

Coyle, J.J., Bardi, E.J. \& Langley, C.J., 2003, The management of business logistics: A supply chain perspective, 7th edn., Thompson Learning, South Western, Quebec.

Creswell, J.W., 2009, Research design: Qualitative, quantitative, and mixed methods approaches, 3rd edn., SAGE, Los Angeles, CA.

Croxton, K.L., Lambert, D.M., García-Dastugue, S.J. \& Rogers, D.S., 2002, 'The demand management process', The International Journal of Logistics Management 13(2), 51-66, viewed08January2019, fromhttps://doi.org/10.1108/09574090210806423

Crum, C. \& Palmatier, G.E., n.d., 'Role of technology in demand planning', Oliver Wight International, viewed 18 February 2018, from http://georgepalmatier.com/whitepapers/role-tech-demand-management.pdf.

Fisher, M.L., Raman, A. \& McClelland, A.S., 2000, 'Rocket science retailing is almost here: Are you ready?', Harvard Business Review 78(4), 115-124, viewed 01 February 2019 from http://0-search.ebscohost.com.ujlink.uj.ac.za/login.aspx?dir

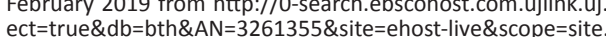

Fritsch, D., 2014, 'How to use ABC classification for inventory management', Easy Stock Blog, viewed 08 January 2019, from http://www.eazystock.com/blog/2014/12/01/ how-to-use-abc-classification-for-inventory-management/.

Fritsch, D., 2015, 'How does ABC analysis affect inventory optimization?', Easy Stock Blog, viewed 08 January 2019, from https://www.eazystock.com/blog/2015/07/10/ how-does-abc-analysis-affect-inventory-optimization/.

G2 Crowd, Inc., 2017, 'Best demand planning software', viewed 21 July 2017, from https://www.g2crowd.com/categories/demand-planning.

Gangadharan, R., 2007, 'Supply chain strategies to manage volatile demand', SCM Pulse, viewed 09 February 2017, from https://scmpulse.wordpress.com/2007/ 02/06/supply-chain-strategies-to-manage-volatile-demand. 
Gilliland, M. \& Platt, J., 2010, The business forecasting deal: Exposing myths, eliminating bad practices, providing practical solutions, ProQuest eBooks Central, viewed 18 February 2018 , from https://0-ebookcentral-proquest-com.ujlink.uj. viewed 18 February 2018, from https://0-ebookcent
ac.za/lib/ujlink-ebooks/detail.action?doclD=537339.

Gilliland, M., Sglavo, U. \& Tashman, L., 2015, Business forecasting: Practical issues and solutions for forecasters, ProQuest eBooks Central, viewed 18 February 2018 from https://0-ebookcentral-proquest-com.ujlink.uj.ac.za/lib/ujlink-ebooks/detail. action?docID $=4206560$

Gupta, S. \& Kumar, N., 2013, 'Accuracy assessment in time series sales forecasting models for FMCG sector', Sona Global Management Review 7(4), viewed 21 March 2018, from http://0-eds.b.ebscohost.com.ujlink.uj.ac.za/eds/ pdfviewer/pdfviewer?vid=1\&sid=7a33dbf8-6642-44af-81d1-a873369ac7e8\%40 sessionmgr103.

Hyndman, R., 2010, 'Forecast estimation, evaluation and transformation', viewed 29 December 2018, from https://robjhyndman.com/hyndsight/forecastmse/.

Hyndman, R., 2011, 'The difference between MSE and MAPE', Stack Exchange, viewed 08 January 2019, from https://stats.stackexchange.com/questions/11636/thedifference-between-mse-and-mape.

Kim, S. \& Kim, H., 2016, 'A new metric of absolute percentage error for intermitten demand forecasts, international journal of forecasting', International Journal of Forecasting 32, 669-670, viewed 18 February 2018, from http://www. sciencedirect.com/science/article/pii/S0169207016000121.

KPMG, 2016a, 'Fast-moving consumer goods: Sector report', KPMG, viewed 18 February 2018, from https://assets.kpmg.com/content/dam/kpmg/br/ pdf/2016/09/fast-moving-consumer-goods.pdf.

KPMG, 2016b, 'Demand-driven supply chain 2.0: A direct link to profitability', KPMG, viewed 17 February 2018, from https://assets.kpmg.com/content/dam/kpmg/ pdf/2016/05/demand-driven-supply-chain-report.pdf.

Levenbach, H., 2011, Ten worst (and some best) demand forecasting practices that impact forecasting performance, viewed 08 April 2019, from http://cpdftraining. org/downloads/APICS2011_Levenbach_10WorstBestPractices.pdf.

Levenbach, H., 2015, 'The myth of the MAPE... and how to avoid it', CPDF: Certified Professional Demand Forecaster, viewed 18 February 2018, from http:// cpdftraining.org/downloads/Levenbach_AccuracyTAPE2015.pdf.

Metcalfe, P., 2012, 'Effective demand planning', MHD Supply Chain Solutions 42(2), 58 , viewed 18 February 2018, from https://search.informit.com.au/documentSumma ry; $\mathrm{dn}=083204458872873$;res=IELBUS.

Michigan State University, 2019, 'Demand planning, how it can help improve SCM', viewed 09 January 2019, from https://www.michiganstateuniversityonline.com/ resources/supply-chain/how-demand-planning-improves-supply-chain/.

Mosalaosi, M., 2016, 'What is the difference between mean absolute error (MAE) the mean percent error (MAPE) and the root mean square error (RMSE)?", Research Gate. Net, viewed 08 January 2019, from https://www.researchgate. net/post/what_is_the_difference_between_Mean_Absolute_Error_MAE_the Mean_Absolute_Percentage_Error_MAPE__and_the_Root_Mean_Square_ Error_RMSE.
Muller, G.H., 1999, 'The importance of demand planning in the management of a fastmoving consumer goods supply chain', Master's thesis, Faculty of Economic and https://ujcontent.uj.ac.za/vital/access/manager/Repository/uj:2761/CONTENT1.

Muro, T., 2016, 'What is data cleansing and why does your CRM need it?', viewed 19 March 2018, from https://www.ringlead.com/blog/data-cleansing-crm-need/.

Myerholtz, B. \& Caffrey, H., 2014, 'Demand forecasting: The key to better supply-chain performance', The Boston Consulting Group, viewed 06 April 2019, from https:// www.bcg.com/publications/2014/supply-chain-management-retail-demandforecasting-the-key-to-better-supply-chain-performance.aspx.

Oracle, 2015, 'Demantra demand management', viewed 17 August 2017, from http:// www.oracle.com/us/products/applications/057040.pdf.

Pricewaterhouse Coopers, 2012, 'South African retail and consumer products outlook 2012-2016', viewed 18 February 2018, from https://www.pwc.co.za/en/assets/ pdf/retail-and-consumer-products-outlook-2012-2016.pdf.

Rouse, M., 2010, 'Demand planning', TechTarget, viewed 05 May 2016, from http:// searchmanufacturingerp.techtarget.com/definition/demand-planning.

Sanchez Rodrigues, V. \& Potter, A., 2013, 'A comparison of FMCG logistics operations in the UK and South Africa', European Business Review 25(4), 351-364, viewed 10 January 2019, from https://doi.org/10.1108/EBR-02-2013-0014.

Sonawane, U., 2011, 'Demand planning in CPG industry - Practising the best practices', Infosys, viewed 18 February 2018, from http://www.infosysblogs.com/supplychain/2011/11/demand_planning_-_practising_t.html.

Stellwagen, E., 2011, 'Forecasting 101: A guide to forecast error measurement statistics and how to use them', Forecast PRO, viewed 08 February 2018, from http://www.forecastpro.com/Trends/forecasting101August2011.html.

Supply Chain Market, 2018, 'Balancing demand and supply with effective sales and operations planning', viewed 12 February 2018, from https://www. supplychainmarket.com/doc/balancing-demand-and-supply-with-effectivesa-0001.

Supply Chain Resource Cooperative, 2004, 'Aligning demand and supply management', NC State University, viewed 11 February 2018, from https://scm.ncsu.edu/scmarticles/article/aligning-demand-and-supply-management.

Veinott, A.F., 2005, Lectures in supply-chain optimization, Dept. of Management Science and Engineering, Stanford University, viewed 06 April 2016, from https:// web.stanford.edu/group/msandehistory/wikiupload/8/84/Veinott_Supply_ Chain_Optimization_Course_Notes.pdf.

Vriens, A. \& Versteijnen, E., 2006, Forecasting and planning in the food industry, White paper, EyeOn, Aarle-Rixtel, viewed 15 March 2018, from https://www.scribd.com/ document/95493166/EyeOn-WP-Forecasting-Planning-in-the-Food-Industry.

Wild, T., 2002, Best practice in inventory management, 2nd edn., Elsevier, Great Britain.

Wood, T., 2012, 'Using mean absolute error for forecast accuracy', Contemporary Analysis (CAN), viewed 27 November 2016, from http://canworksmart.com/ using-mean-absolute-error-forecast-accuracy. 